\title{
Mercury Loss From Dental Amalgam Fillings
}

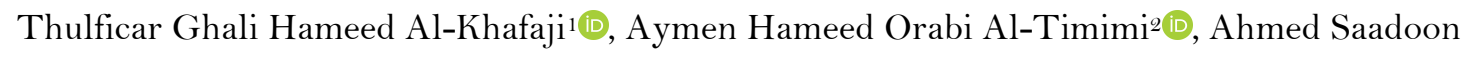

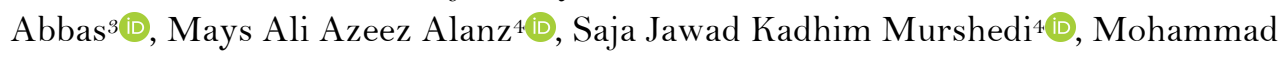

\author{
Khursheed Alam ${ }^{5}$ (1)
}

${ }^{1}$ Conservative Dentistry Department, College of Dentistry, University of Babylon, Babylon, Iraq.

${ }^{2}$ Oral and Maxillofacial Surgery Department, College of Dentistry, University of Babylon, Babylon, Iraq.

${ }^{3}$ Chemistry Department, College of Science, University of Babylon, Babylon, Iraq.

${ }^{4}$ Iraqi Ministry of Health, Babylon, Iraq.

${ }^{5}$ Orthodontic Department, College of Dentistry, Jouf University, Sakaka, Saudi Arabia.

Author to whom correspondence should be addressed: Dr. Thulficar G. H. Al-Khafaji, College of Dentistry, University of Babylon, Aljamea sq.60th street, Babylon, Iraq. Phone: +9647811829269. E-mail: thulficar@yahoo.com.

Academic Editors: Alessandro Leite Cavalcanti and Wilton Wilney Nascimento Padilha

Received: 27 September 2019 / Accepted: 19 March 2020 / Published: 06 April 2020

How to cite this article: Al-Khafaji TGH, Al-Timimi AHO, Abbas AS, Alanz MAA, Murshedi SJK, Alam MK. Mercury
loss from dental amalgam fillings. Pesqui Bras Odontopediatria Clín Integr. 2020; 20:e5267.
https://doi.org/10.1590/pboci.2020.061

\begin{abstract}
Objective: To compare the amount of mercury in new and old dental amalgam restorations. Material and Methods: This study analyzed twenty samples of dental amalgam restorations, dividing into two groups. Group 1 consisted of samples of new dental amalgam restoration $(n=10)$ and group 2 consisted of samples of old dental amalgam restoration (5-years old) $(n=10)$. In each group, the mercury involved in the dental amalgam restoration was calculated using the cloud point extraction (CPE) method. The new dental amalgam restorations are taken from the patients' mouth after condensation and analyzed directly after setting. The old dental amalgam restorations are removed from the patients' mouth, after 5 years of use by the patients, and then they are analyzed. The independent-samples t-test was used to analyze the differences $(\mathrm{p}<0.05)$. Results: For new amalgam restorations, the mean of mercury was $0.1281 \mu \mathrm{g} / \mathrm{mL}$, while for old restorations it was $0.1029 \mu \mathrm{g} / \mathrm{mL}$. There was a significant difference between the new and old amalgam restorations in the amount of mercury available $(\mathrm{p}<0.001)$. Conclusion: There is a significant loss of mercury over a five years period in the patient mouth.
\end{abstract}

Keywords: Dental Materials; Dental Alloys; Dental Amalgam; Mercury. 


\section{Introduction}

Amalgam is a direct restoration that fills a cavity in a tooth structure to restore its shape and function to its normal condition. This cavity is done inside the tooth to remove dental caries [1]. Dental amalgam is an alloy result from the reaction of mercury $(\mathrm{Hg})$ with silver-tin $(\mathrm{Ag}-\mathrm{Sn})$. This is in addition to varying amounts of copper $(\mathrm{Cu})$ and trace amounts of zinc $(\mathrm{Zn})[2]$. After the reaction of the mercury $(\mathrm{Hg})$ with the powder alloy, around half of the final filling material consists of $\mathrm{Hg}$, and the remaining amount is a combination of $\mathrm{Ag}$, $\mathrm{Sn}$ and $\mathrm{Cu}[1]$.

The statistical analysis of the American population from 2001 to 2004 showed that more than 180 million of the American people have more than 1 billion dental restorations, and most of these restorations are dental amalgam [3].

There is a debate about the safety of mercury involved in the final restoration of the dental amalgam after its placement inside the tooth. One assumption said that dental amalgam does not release amalgam after the placement of the restoration. The US Food and Drug Administration (FDA) showed that amalgam loses traces of $\mathrm{Hg}$ vapor [4]. The debate has continued untill the moment whether mercury loss from the dental amalgam restoration is safe or not and the safety threshold differs in different individuals [5]. Therefore, this research aims to calculate the amount of $\mathrm{Hg}$ in new and old dental amalgam restorations.

\section{Material and Methods}

Study Design and Sample

This experimental study analyses twenty samples of dental amalgam restorations $(\mathrm{n}=20)$, after dividing them into two groups. Group 1 consisted of samples of new dental amalgam restoration $(n=10)$ and group 2 consisted of samples of old dental amalgam restoration (5-years old) ( $n=10)$.

In each group, the mercury involved in the dental amalgam restoration is calculated using the cloud point extraction $(\mathrm{CPE})$ method [6-8] and then comparing the results between the two groups. The new dental amalgam restorations are taken from the patients' mouth (10 patients) after condensation and analyzed directly after setting. The old dental amalgam restorations are removed from the patients' mouth (10 patients), after 5 years of use by the patients, and then they are analyzed.

The cloud point extraction method was done with optimal conditions ( $\mathrm{pH}$ value, volume of the reagent used for detection of the mercury, volume of the surfactant used for the detection of the mercury, equilibrium temperature and incubation time) to show which is the better condition or parameter in which we can calculate the amount of mercury in the dental amalgam restoration. So, the optimum conditions were $9.6 \mathrm{pH}, 0.5 \mathrm{~mL}$ of the reagent (diphenylthiocarbazone) $0.5 \mathrm{~mL}$ of the surfactant (Triton X-114, Merck KGaA, Darmstadt, Germany), $50^{\circ} \mathrm{C}$ temperature, and $25 \mathrm{~min}$. incubation time. In addition, validation of this method of cloud point extraction for determination of the un-known mercury available in the dental amalgam restoration is done by determination of the known concentration of mercury available in the form of salt (mercuric chloride) [9,10].

The equipments which are used for doing the procedure with cloud point extraction were the spectrophotometer (Model 1600, Shimadzu Corp., Kyoto, Japan) with double beam UV-visible recording, a digital pH meter (inoLab pH 720, Xylem Analytics Germany Sales GmbH \& Co. KG WTW, Weilheim, Germany) for all pH measurements, a thermo bath (Circulator England, Thermo Fisher Scientific Inc., London, England) maintained as the best incubation temperature for the cloud point extraction, and phase separation was assisted using a centrifuge PLC 03 (Gemmy Industrial Corp., Taipei, Taiwan). 


\section{Data Analysis}

Data were analyzed using IBM SPSS Statistics for Windows, Version 19.0 (IBM Corp., Armonk, NY, USA). The independent samples t-test was used to analyze the differences. The significance level has been considered 0.05.

Ethical Aspects

The study was conducted in accordance with the ethical principles of the Helsinki Declaration. This study was approved by the local ethics committee, Protocol No. COD\#UoB\#EthB-00923.

\section{Results}

The results are shown in Table 1 . There is a significant difference between the two groups in the amount of mercury available in dental amalgam restoration (Table 2). So, there is a significant loss in mercury over 5 years period of using mercury by the patient and subjecting mercury to different conditions such as drinking hot tea or coffee and doing the polishing procedure in the dental clinic.

Table 1. The $\mathrm{Hg}$ concentration in the new and old amalgam restoration.

\begin{tabular}{ccc}
\hline $\begin{array}{c}\text { Sample } \\
\text { No. }\end{array}$ & $\begin{array}{c}\text { New Dental Amalgam Restoration } \\
\mathrm{Hg} \text { concentration }(\mu \mathrm{g} / \mathrm{mL})\end{array}$ & $\begin{array}{c}\text { Old Dental Amalgam Restoration } \\
\text { Hg concentration }(\mu \mathrm{g} / \mathrm{mL})\end{array}$ \\
\hline 1 & 0.138 & 0.104 \\
2 & 0.118 & 0.103 \\
3 & 0.134 & 0.099 \\
4 & 0.137 & 0.098 \\
5 & 0.120 & 0.110 \\
6 & 0.125 & 0.104 \\
7 & 0.117 & 0.109 \\
8 & 0.128 & 0.099 \\
9 & 0.131 & 0.097 \\
10 & 0.133 & 0.106 \\
\hline
\end{tabular}

Table 2. Statistical analysis of the measurements.

\begin{tabular}{cccccc} 
Groups & N & Mean & $\begin{array}{c}\text { Standard } \\
\text { Deviation }\end{array}$ & $\begin{array}{c}\text { Standard } \\
\text { Error Mean }\end{array}$ & p-value \\
\hline $\begin{array}{c}\text { New Dental Restoration } \\
\text { Hg Concentration }(\mu \mathrm{g} / \mathrm{mL})\end{array}$ & 10 & 0.1281 & 0.00778 & 0.00246 & $<0.0001$ \\
$\begin{array}{c}\text { Old Dental Restoration } \\
\mathrm{Hg} \text { Concentration }(\mu \mathrm{g} / \mathrm{mL})\end{array}$ & 10 & 0.1029 & 0.00458 & 0.00145 & \\
\hline
\end{tabular}

\section{Discussion}

People doing several dental amalgam fillings for restoration of their teeth could be a major source of exposure to inorganic $\mathrm{Hg}$. The FDA considered dental amalgam fillings safe for adults, 6 years children and children above 6 years. People allergic to mercury or any other metals in the dental amalgam filling should not use dental amalgam, because this may result in an oral lesion or any contact reaction [1,11-13].

Most of the studies investigated the release of $\mathrm{Hg}$ vapor from amalgam restoration through the investigation of the amount of $\mathrm{Hg}$ in blood or urine. In this study, the loss or release of mercury is investigated through the mathematical calculation of the concentration of the $\mathrm{Hg}$ in the new amalgam and comparing it with the mercury concentration in the old amalgam, using the cloud point extraction (CPE) method. This 
method is a useful technique for the detection of trace metals in some substances [8]. It has several advantages since it is a straightforward procedure, relatively inexpensive and environmentally safe [14]. It involves a set of analytical methods [6]. Recently, the cloud point extraction method and its procedure of metal chelate extraction have been respected [7].

It was assumed that dental amalgam is inert and does not lose mercury after its placement onto the tooth surface [15]. The US Food and Drug Administration (FDA) informed that the release of the mercury vapor is low, and both of ADA agency and the American Dental Association (ADA) agency agreed that dental amalgam restoration is safe $[1,16]$. While, other studies investigated the mercury level in the blood, urine and assumed that it has an effect on the health of the patient who has dental amalgam filling in his mouth [17-22]. In the current study, the results show that the change in the amount of $\mathrm{Hg}$ available in the amalgam restoration is significant over the 5 years period, since the difference between the new and old amalgam filling in the amount of mercury is significant. So, amalgam filling could have an effect on patient health due to significant loss of $\mathrm{Hg}$ from amalgam restoration.

In this study, the loss of $\mathrm{Hg}$ is measured directly from the amalgam filling at different periods of time, while other studies measured it indirectly by measuring its level in the urine or blood and correlated it to the dental amalgam restoration of the patient [17-22]. Anyway, in the indirect measurement, the increase in the level of the mercury in the blood and urine could have different sources other than dental amalgam restoration, such as daily occupational exposure to mercury.

Further future studies are recommended to investigate the association between the loss of mercury and the clinical health problems of the patient. In addition to that, it is recommended to do an investigation on the mercury available in the dental amalgam restoration in more groups at different time scales, such as less than 5 years and more than five years. Another recommendation is to select a larger number of samples.

\section{Conclusion}

There is a significant difference between the new and 5-years old dental amalgam filling in the level of mercury. This shows that the loss of mercury over a 5 years period in the patient mouth is significant.

\section{Authors' Contributions}

\begin{tabular}{|c|c|c|}
\hline TGHA & (iD) $0000-0003-4383-2918$ & $\begin{array}{l}\text { Conceptualization, Methodology, Formal Analysis, Investigation, Writing - } \\
\text { Original Draft Preparation and Writing - Review and Editing. }\end{array}$ \\
\hline AHOA & (iD) $0000-0003-2458-6934$ & $\begin{array}{l}\text { Conceptualization, Methodology, Formal Analysis, Investigation, Writing - } \\
\text { Original Draft Preparation and Writing - Review and Editing. }\end{array}$ \\
\hline ASA & (iD) $0000-0003-4479-2161$ & $\begin{array}{l}\text { Conceptualization, Investigation, Writing - Original Draft Preparation and } \\
\text { Writing - Review and Editing. }\end{array}$ \\
\hline MAAA & (iD) $0000-0002-3302-125 \mathrm{X}$ & $\begin{array}{l}\text { Conceptualization, Investigation, Writing - Original Draft Preparation and } \\
\text { Writing - Review and Editing. }\end{array}$ \\
\hline SJKM & (iD) $0000-0003-0300-3808$ & $\begin{array}{l}\text { Conceptualization, Writing - Original Draft Preparation and Writing - Review } \\
\text { and Editing. }\end{array}$ \\
\hline MKA & (iD) $0000-0001-7131-1752$ & $\begin{array}{l}\text { Conceptualization, Formal Analysis, Writing - Original Draft Preparation and } \\
\text { Writing - Review and Editing. }\end{array}$ \\
\hline
\end{tabular}

\section{Financial Support}

None. 


\section{Conflict of Interest}

The authors declare no conflicts of interest.

\section{References}

[1] US Food and Drug Administration. Dental amalgam. About dental amalgam fillings. Available from: https://www.fda.gov/medical-devices/dental-amalgam/about-dental-amalgam-fillings. [Accessed August 20, 2019].

[2] Roberson TM, Heymann H, Swift EJ, Sturdevant CM. Sturdevant's Art and Science of Operative Dentistry. 5th ed. St. Louis: Mosby; 2006.

[3] Richardson GM, Wilson R, Allard D, Purtill C, Douma S, Gravière J. Mercury exposure and risks from dental amalgam in the US population, post-2000. Sci Total Environ 2011; 409(20):4257-68. https://doi.org/10.1016/j.scitotenv.2011.06.035

[4] US Food and Drug Administration, HHS. Dental devices: classification of dental amalgam, reclassification of dental mercury, designation of special controls for dental amalgam, mercury, and amalgam alloy. Final rule. Fed Regist 2009; 74(148):38685-714.

[5] Berlin M, Zalups RK, Fowler BA. Mercury. In: Nordberg GF, Fowler BA, Nordberg M, Friberg LT. Handbook on the Toxicology of Metals. 3rd. ed. Burlington: Academic Press; 2007. Chapter 33, pp. 675-729.

[6] Watanabe H, Tanaka H. A non-ionic surfactant as a new solvent for liquid-liquid extraction of zinc(II) with 1-(2pyridylazo)-2-naphthol. Talanta 1978; 25(10):585-9. https://doi.org/10.1016/0039-9140(78)80151-9

[7] Yazdi AS. Surfactant-based extraction methods. Trends Analyt Chem 2011; 30(6):918-29. https://doi.org/10.1016/j.trac.2011.02.010

[8] Espinosa Bosch M, Ruiz Sánchez AJ, Sánchez Rojas F, Bosch-Ojeda C. Analytical determination of furosemide: the last researches. Int J Pharm Bio Sci 2013; 3(4):168-81.

[9] Wilhelm SM, Liang L, Kirchgessner D. Identification and properties of mercury species in crude oil. Energ Fuels 2006; 20(1):180-6. https://doi.org/10.1021/ef0501391

[10] Pavageau MP, Morin A, Seby F, Guimon C, Krupp E, Pécheyran C, et al. Partitioning of metal species during an enriched fuel combustion experiment. speciation in the gaseous and particulate phases. Environ Sci Technol 2004; 38(7):2252-6. https://doi.org/10.1021/es034408i

[11] Clarkson TW, Friberg L, Hursh JB, Nylander M. The Prediction of Intake of Mercury Vapor from Amalgams. In: Clarkson ThW, Friberg L, Nordberg GF, Sager PR. Biological Monitoring of Toxic Metals. Boston: Springer; 1988.

[12] Clarkson ThW, Friberg L, Nordberg GF, Sager PR. Biological monitoring of toxic metals. New York: Plenum Press; 1988. 698p.

[13] World Health Organization. Inorganic mercury. Available from: https://apps.who.int/iris/handle/10665/40626. [Accessed on August 20, 2019].

[14] Kadhim KH, Alsharifi AN, Abbas AS. Separation and preconcentration for determination of ultra trace of chromium(III) and zinc(II) using spectrofluorimetry techniques. Asian J Chem 2014; 26:S139-S142.

[15] Homme KG, Kern JK, Haley BE, Geier DA, King PG, Sykes LK, et al. New science challenges old notion that mercury dental amalgam is safe. Biometals 2014; 27(1):19-24. https://doi.org/10.1007/s 10534-013-9700-9

[16] American Dental Association. Statement on dental amalgam. Available from: http://www.ada.org/1741.aspx. 2013 [Accessed August 20, 2019].

[17] Abraham JE, Svare CW, Frank CW. The effect of dental amalgam restorations on blood mercury levels. J Dent Res 1984; 63(1):71-3. https://doi.org/10.1177/00220345840630011801

[18] Woods JS, Martin MD, Leroux BG, DeRouen TA, Leitão JG, Bernardo MF, et al. The contribution of dental amalgam to urinary mercury excretion in children. Environ Health Perspect 2007; 115(10):1527-31. https://doi.org/10.1289/ehp.10249

[19] Eslami H, Ostadi A, Falsafi P, Mehrbani SP, Dolatkhah H, Fakhrzadeh V, et al. Dental amalgam exposure and urinary mercury levels in dentists. Pharmacophore 2017; 8(68):e-117356.

[20] Snapp KR, Boyer DB, Peterson LC, Svare CW. The contribution of dental amalgam to mercury in blood. J Dent Res 1989; 68(5):780-5. https://doi.org/10.1177/00220345890680050501

[21] Miriam Varkey I, Shetty R, Hegde A. Mercury exposure levels in children with dental amalgam fillings. Int J Clin Pediatr Dent 2014; 7(3):180-5. https://doi.org/10.5005/jp-journals-10005-1261

[22] Eyeson J, House I, Yang YH, Warnakulasuriya KAAS. Relationship between mercury levels in blood and urine and complaints of chronic mercury toxicity from amalgam restorations. $\mathrm{Br}$ Dent J 2010; $208(4)$ :E7. https://doi.org/10.1038/sj.bdj.2010.181 